\title{
Scavenging Properties of the Polyamine Functionalized Gels Based on the Glycidyl Methacrylate Terpolymers
}

\author{
Agnieszka Bukowska1, Wiktor Bukowski1 ${ }^{*}$, Maciej Pytel ${ }^{2}$ \\ ${ }^{1}$ Faculty of Chemistry, Rzeszów University of Technology, Rzeszów, Poland \\ ${ }^{2}$ Faculty of Mechanical Engineering and Aeronautics, Rzeszów University of Technology, Rzeszów, Poland \\ Email:"wbuk@prz.edu.pl
}

Received 8 October 2015; accepted 8 November 2015; published 11 November 2015

Copyright (C) 2015 by authors and Scientific Research Publishing Inc.

This work is licensed under the Creative Commons Attribution International License (CC BY). http://creativecommons.org/licenses/by/4.0/

(c) (7) Open Access

\begin{abstract}
Scavenging abilities of the ethylenediamine, diethylenetriamine and tris(2-aminoethyl)amine functionalized resins derived from the low cross-linked glycidyl methacrylate-styrene gels in relation to the selected transition metal ions and organic (acid chlorides) electrophiles were explored. The synergetic effects of the solvents were found for the metal ion uptake. In this case a pair of solvents capable simultaneously to swell the hydrophobic core of the resins and interact with the polar amine groups turned out to be a more effective medium for activation of the nucleophilic functionalities of the resins. The resin with ethylenediamine moieties proved to be effective in scavenging acyl chlorides from methylene chloride as well. However, it did not provide complete removing sulphonyl chlorides from the solutions. These organic electrophiles were removed effectively by the resins bearing tris(2-aminoethyl)amine functionalities.
\end{abstract}

\section{Keywords}

Scavenging Resins, Polyamine Functionalized Resins, Glycidyl Methacrylate Terpolymers

\section{Introduction}

Homogeneous or heterogeneous catalysts based on transition metals, including noble metals, have the tremendous synthetic potential [1]. They are important in particular from the point of view of catalyzing different hydrogenation, oxidation and cross-coupling reactions. These groups of organic transformations have found the numerous practical applications in synthesis of drugs and other biologically active compounds, as well as ad-

${ }^{*}$ Corresponding author.

How to cite this paper: Bukowska, A., Bukowski, W. and Pytel, M. (2015) Scavenging Properties of the Polyamine Functionalized Gels Based on the Glycidyl Methacrylate Terpolymers. Open Journal of Polymer Chemistry, 5, 63-73.

http://dx.doi.org/10.4236/ojpchem.2015.54008 
vanced materials.

The use of transition metals in preparation of pharmaceutical ingredients often involves the risk of contamination of the final products with toxic impurities. The acceptable limits of the heavy metal residuals in pharmaceuticals are set usually at the ppm level. Initially, the classical techniques of extraction and precipitation were applied to achieve the desire level of impurities in the final products. These methods are usually time-consuming and often expensive and inefficient. Because of that, the novel active sorbents which are capable to remove nearly quantitatively metal ion impurities from organic solutions have been developed in academic and industrial laboratories over the last decades [2]-[10].

The dedicated scavenging resins were firstly taken into consideration in the mid-1990s independently by groups of Kaldor, Flynn and Hodge [11]-[14]. They described an idea of utilizing different reactive polymers in purification of organic products. The new methodologies of the purification were named as solid phase scavenging, complementary molecular reactivity and molecular recognition (CMR/R) or polymer-supported quench (PSQ). They based on differences in the reactivity of impurities and desired products in relation to the functional groups present in the polymer structure. The new possibilities of simple and effective purification using the special reactive polymers were fast accepted by researchers as a very useful tool for combinatorial chemistry. They became the effective alternative to the time-consuming and troublesome classical methods of purification.

The several specific sorbents based on inorganic and organic materials were commercialized to date. They are offered individually or as metal scavenger kits contained the reactive sorbents (inorganic or polymeric) bearing thiol, tiourea, guanidine, polyamine, or imidazole moieties as specific ligands capable to immobilize different transition metal ions.

Among the numerous reactive sorbents described previously, the polymers bearing polyamine (ethylenediamine, diethylenetriamine or tris(2-aminoethyl)amine) functionalities have attracted attention of researchers especially often. It results from their ability to complex many transition metals [3] [4] [7]-[9]. Thanks to that they have been often utilized as reactive sorbents for purification liquids from the metal ion impurities [3] [7]-[9].

In this work we present the scavenging properties of the amine functionalized resins based on the GMA gels developed in our laboratory [15]. The resins are explored as scavengers for the selected transition metal ions (Pd(II), Ni(II) and $\mathrm{Cu}(\mathrm{II})$ ) and organic electrophiles (acyl and sulphonyl chlorides).

\section{Experimental}

\subsection{Materials, Analysis and Instrumental}

Nickel(II) chloride hexahydrate or nickel(II) acetate tetrahydrate, palladium(II) acetate (99.9+\%), and copper(II) acetate monohydrate (metal ion sources) were purchased from Sigma-Aldrich. The amine functionalized resins (1.1-1.3-2.1-2.3, Scheme 1 and Table 1) were derived from the GMA resins [15]. They were prepared using the procedure described previously [16]. The GMA resins were synthesized from the mixture of glycidyl methacrylate (GMA, 20 mol-\%), styrene (S, 77 mol-\%) and diethyleneglycol dimethacrylate (DEGDMA, 3 mol-\%, resin 1) or divinylbenzene (DVB, 3 mol-\%, resin 2). Solvents and analytical reagents were used as received from Aldrich, Fluka or POCh.

The swelling of the resins in the selected solvents and binary solvent systems were assessed using $2.5 \mathrm{ml}$ polypropylene syringes. The following procedure was applied: $0.2 \mathrm{~g}$ samples of the dry resin beads were placed in the syringes equipped with filters and Luer valves and the appreciate solvents were added in excess. After 30 60 minutes, when the swelling equilibria were achieved, an excess of the solvents was removed by means of

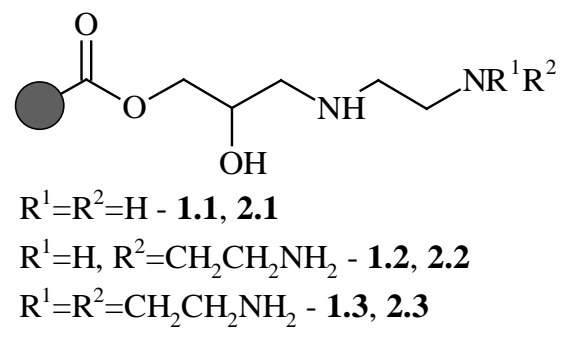

Scheme 1. Polyamine resins. 
Table 1. Resin characteristics.

\begin{tabular}{|c|c|c|c|c|c|c|}
\hline \multicolumn{3}{|c|}{ GMA resins } & \multicolumn{4}{|c|}{ Polyamine resins } \\
\hline & & \multirow[b]{2}{*}{$\begin{array}{l}\text { Epoxy group loading, } \\
\mathrm{mmol} / \mathrm{g}\end{array}$} & \multirow[b]{2}{*}{ Polyamine } & \multirow[b]{2}{*}{ Abbr. } & \multicolumn{2}{|c|}{ Nitrogen content } \\
\hline \multicolumn{2}{|l|}{ Abbr. } & & & & wt.\% & $\mathrm{mmol} \mathrm{N} / \mathrm{g}$ \\
\hline \multirow{3}{*}{ 20\%GMA-3\%DEGDMA-77\%S } & \multirow{3}{*}{1} & \multirow{3}{*}{1.37} & EDA & 1.1 & 3.28 & 2.34 \\
\hline & & & DETA & 1.2 & 4.79 & 3.42 \\
\hline & & & TAEA & 1.3 & 5.53 & 3.95 \\
\hline \multirow{3}{*}{ 20\%GMA-3\%DVB-77\%S } & \multirow{3}{*}{2} & \multirow{3}{*}{1.40} & EDA & 2.1 & 3.61 & 2.58 \\
\hline & & & DETA & 2.2 & 4.56 & 3.26 \\
\hline & & & TAEA & 2.3 & 5.55 & 3.96 \\
\hline
\end{tabular}

plungers. The swelling ratio was calculated as $\Delta V=\left(m_{d}-m_{s}\right) /\left(\rho \cdot m_{s}\right) ; m_{d}$ and $m_{s}$-masses of the dry and swelled resin samples, respectively, and $\rho$-solvent density.

FT-IR spectra of the resins were recorded using a Thermo Scientific Nicolet 8700 spectrometer and KBr pellets. Diffuse reflectance UV-Vis-NIR (DR UV-Vis-NIR) spectra of the resins were recorded using a Jasco V-670 spectrophotometer equipped with a Jasco ISN-723 UV-Vis NIR $60 \mathrm{~mm}$ integrating sphere and $\mathrm{BaSO}_{4}$ as a standard.

Concentrations of the individual metal ions in the post-uptake solutions were determined using UV-Vis methods described previously in literature (nickel(II) [17] and palladium(II) [18] ions). A Thermo Scientific Helios $\beta$ spectrophotometer was used for performing the analyses.

The loading of the metal ions immobilized on the amine resins were determined by a ICP method using a GBC ICP-OES Integra XL spectrometer $(\mathrm{Cu}(\mathrm{II})-\lambda=24.754 \mathrm{~nm}, \mathrm{Ni}(\mathrm{II})-\lambda=341.476 \mathrm{~nm}$, and $\mathrm{Pd}(\mathrm{II})$ ions $-\lambda=$ $340.458 \mathrm{~nm}$ ). Mineralization of the samples for analysis (ca. 5 - $10 \mathrm{mg}$ ) was performed in concentrated nitric acid (5.0 ml) using a Plazmatronika Uni Clever II microwave mineralizer.

\subsection{Metal Ion Uptake-General Procedure}

Two series amine functionalized resins bearing ethylenediamine (EDA), diethylenetriamine (DETA) and tris(2aminoethyl)amine (TAEA), and cross-linked with DEGDMA (resins abbreviated as 1.1, 1.2 and 1.3) and DVB (abbreviated as 2.1, 2.2 and 2.3) were used in the metal ion uptake experiments. Samples of resins 1.1-1.3 and 2.1-2.3 ( $0.1 \mathrm{~g}$ ) were placed into the $5 \mathrm{ml}$ glass vials equipped with screw tops and $\mathrm{Ni}(\mathrm{II})$ or $\mathrm{Pd}(\mathrm{II})$ ion solutions ( $2 \mathrm{ml}, 0.4-0.8 \mathrm{mmol})$ in an organic solvent were added. The vials were then sealed immediately, placed on a vibration shaker, and shaken for $5,10,20,40$ or 60 minutes. After that the resins were filtered off and the residuals of $\mathrm{Ni}(\mathrm{II})$ or $\mathrm{Pd}(\mathrm{II})$ ions in the post-uptake solutions were analyzed using the aforesaid UV-Vis procedures.

\subsection{The Loading Capacity of the Amine Resins in Relation to Cu(II), Ni(II) and Pd(II) Ions}

Samples of resins 2.1-2.3 (0.1 g) were placed into $5 \mathrm{ml}$ vials and the solutions consisting of the equimolar quantities of $\mathrm{Cu}(\mathrm{II}), \mathrm{Ni}(\mathrm{II})$ and $\mathrm{Pd}(\mathrm{II})$ ions were added. The sealed vials were then shaken 24 hours at room temperature. Next, the resins were filtered off using the polypropylene syringes equipped with Luer valves and cotton filters, rinsed several times with the solvent used in the appropriate experiments and dried under reduced pressure at $40^{\circ} \mathrm{C}$. The loadings of the metal ions immobilized on the resins were determined by ICP-OES.

\subsection{Competitive Uptake of $\mathrm{Cu}($ II), $\mathrm{Ni}$ (II), and Pd (II) Ions}

Samples of resins 2.1-2.3 (0.05 g) were placed in $5 \mathrm{ml}$ vials and the solutions consisting of the equimolar quantities of $\mathrm{Cu}(\mathrm{II}), \mathrm{Ni}(\mathrm{II})$, and Pd (II) acetates dissolved in the mixture of THF and water (1:1 v/v) were added. The mixtures were shaken for $24 \mathrm{~h}$. The final products were then filtered off, washed carefully with the THF-water mixture and dried under reduced pressure. The loadings of the metal ions immobilized on the resins were determined using ICP-OES. 


\subsection{Acid Chlorides Uptake-General Procedure}

Samples of resins 2.1-2.3 (0.1 g) were placed into the $5 \mathrm{ml}$ vials equipped with screw tops and acid chlorides solutions ( $1 \mathrm{ml}, 1 / 3$ eq. mmol in relation to amine groups) in methylene chloride were added. The sealed vials were shaken for the fixed periods of time. The residuals of acid chlorides in the post-uptake solutions were determined chromatographically.

\section{Results and Discussion}

Previously, we described that the resins bearing EDA, DETA and TAEA moieties immobilized on the low cross-linked glycidyl methacrylate terpolymers are able to remove $\mathrm{Co}(\mathrm{II}), \mathrm{Cu}(\mathrm{II}), \mathrm{Fe}(\mathrm{III})$, and $\mathrm{Mn}(\mathrm{II})$ ions from organic solutions nearly immediately when the solvents sufficiently compatible with the resins are applied [16]. It was also found that the reactivity of the amine functionalized resins decreased dramatically in an incompatible medium. These findings were the reason for broadening our research on two further transition metal ions used for preparation of different catalytic systems-nickel(II) and palladium(II) ions. Removing the residuals of these toxic ions from the products of catalytic reactions, particularly in the case of the use of the latter as pharmaceutical components, is an important practical problem. We also decided to explore the polyamine gels developed in our laboratory as scavengers for acyl and sulphonyl chlorides. These organic electrophiles are often used for the synthesis of amides and sulphonamides, the compounds important from a point of view of medicinal chemistry.

\subsection{The Affinity of the Amine Resins to Nickel(II) Ions}

The experiments including Ni(II) ions and resins 1.1-1.3 and 2.1-2.3 were performed using methanol and its mixtures with methylene chloride as a uptake medium, similarly to our previous work [16]. Nickel(II) chloride was used as a source of $\mathrm{Ni}(\mathrm{II})$ ions. This salt is sufficiently soluble both in methanol and its mixtures with $\mathrm{CH}_{2} \mathrm{Cl}_{2}$, but insoluble in pure methylene chloride.

It was noted that the resins bearing EDA $(\mathbf{1 . 1}, \mathbf{2 . 1})$ and TAEA $(1.3,2.3)$ moieties show the moderate affinity to $\mathrm{Ni}(\mathrm{II})$ ions in pure methanol. The reactivity of the resins depended partly on the nature of the cross-linking monomers used for preparation of the GMA resins. Resin 1.3 bearing TAEA and DEGDMA moieties was able to remove about $60 \% \mathrm{Ni}(\mathrm{II})$ ions dissolved within 60 min while resin 1.1 consisting of EDA groups more than 30\%. In the case of the resins cross-linked with DVB, the one bearing EDA groups (2.1) turned out to be only slightly more active than the resins with TAEA moieties (2.3). The efficiency of these two resins in removing $\mathrm{Ni}(\mathrm{II})$ ions from $\mathrm{MeOH}$ solutions did not exceed 50\%. The DETA functionalized resins (1.2 and 2.2) showed very low affinity to $\mathrm{Ni}(\mathrm{II})$ ions in $\mathrm{MeOH}$ (Table 2).

Based on the fact that EDA, DETA and TAEA are capable to form durable complexes with Ni(II) ions [19] one could expect that the resins with these amines immobilized on a polymer core ought to show rather similar ability to $\mathrm{Ni}(\mathrm{II})$ ions, particularly if the functionalized polymers show similar swelling in $\mathrm{MeOH}$ [16]. Only the resins bearing TAEA moieties $(\mathbf{1 . 3}, \mathbf{2 . 3})$ swell in this solvent slightly stronger. So, similarly to the observation made previously for the experiments of cobalt(II), iron(III), and manganese(II) ion uptake [16], it was difficult to understand so strong diversity in the affinity of the explored amine resins to $\mathrm{Ni}(\mathrm{II})$ ions in $\mathrm{MeOH}$.

Furthermore, the scavenging ability of the resins in relation to Ni(II) ions in methanol turned out to be clearly different than those observed for $\mathrm{Cu}(\mathrm{II})$ ions. The latter were scavenged from $\mathrm{MeOH}$ by $\mathbf{1 . 1}$ and $\mathbf{2 . 1}$ quantitatively within 10 min [16] while the former only in about $50 \%$ within 60 min.

The scavenging ability of the explored resins in relation to $\mathrm{Ni}(\mathrm{II})$ ions increased dramatically when the mixture of methanol and methylene chloride was used. The simultaneous use of these two solvents in 1:1 v/v ratio activated the resins so strongly that they were able to remove $\mathrm{Ni}(\mathrm{II})$ ions from the model solutions quantitatively or nearly quantitatively within $10-20$ minutes (Table 2). These findings showed once more that the swelling of polymer beads plays an important role in activation of the nonporous, gel type polyamine scavengers.

To learn the donor ability of the EDA, DETA and TAEA moieties immobilized on the GMA gel in little more detail, a series of additional experiments were performed including 2.1-3, nickel(II) chloride and nickel(II) acetate in the mixed $\mathrm{MeOH}$ and $\mathrm{CH}_{2} \mathrm{Cl}_{2}$ medium. The resins were shaken for 24 hours with the equivalent quantities of $\mathrm{Ni}(\mathrm{II})$ ions (in relation to the loading of amine groups). Green, blue, sapphire (or violet) beads of the polymer supported $\mathrm{Ni}(\mathrm{II})$-polyamine complexes were obtained depending on the amine moieties (Table 3). It was found that the colors of the complexes correlated with the N/Ni ratio calculated based on the results of elementary analysis and the immobilized polyamines. The complexes with EDA functionalities marked by the N/Ni ratio 
Table 2. Uptake of Ni(II) ions by the polyamine functionalized resins characteristics.

\begin{tabular}{|c|c|c|c|}
\hline Polyamine resin & Solvent & Time (min) & $\mathrm{Ni}(\mathrm{II})$ ion uptake (\%) \\
\hline \multirow{2}{*}{1.1} & $\mathrm{MeOH}$ & 60 & 33 \\
\hline & $\mathrm{MeOH}-\mathrm{CH}_{2} \mathrm{Cl}_{2}(1: 1 \mathrm{v} / \mathrm{v})$ & 5 & 92 \\
\hline \multirow{2}{*}{1.2} & $\mathrm{MeOH}$ & 60 & 4 \\
\hline & $\mathrm{MeOH}-\mathrm{CH}_{2} \mathrm{Cl}_{2}(1: 1 \mathrm{v} / \mathrm{v})$ & 5 & 94 \\
\hline \multirow{2}{*}{1.3} & $\mathrm{MeOH}$ & 60 & 64 \\
\hline & $\mathrm{MeOH}-\mathrm{CH}_{2} \mathrm{Cl}_{2}(1: 1 \mathrm{v} / \mathrm{v})$ & 5 & 95 \\
\hline \multirow{2}{*}{2.1} & $\mathrm{MeOH}$ & 60 & 47 \\
\hline & $\mathrm{MeOH}-\mathrm{CH}_{2} \mathrm{Cl}_{2}(1: 1 \mathrm{v} / \mathrm{v})$ & 5 & 95 \\
\hline \multirow{2}{*}{2.2} & $\mathrm{MeOH}$ & 60 & 2 \\
\hline & $\mathrm{MeOH}-\mathrm{CH}_{2} \mathrm{Cl}_{2}(1: 1 \mathrm{v} / \mathrm{v})$ & 5 & 93 \\
\hline \multirow{2}{*}{2.3} & $\mathrm{MeOH}$ & 60 & 37 \\
\hline & $\mathrm{MeOH}-\mathrm{CH}_{2} \mathrm{Cl}_{2}(1: 1 \mathrm{v} / \mathrm{v})$ & 5 & 94 \\
\hline
\end{tabular}

Table 3. Characteristics of the polymer supported polyamine-Ni(II) complexes.

\begin{tabular}{|c|c|c|c|c|c|c|}
\hline \multirow{2}{*}{ Resin } & \multirow{2}{*}{$\begin{array}{l}\mathrm{Ni}(\mathrm{II}) \text { ion } \\
\text { precursor }\end{array}$} & \multicolumn{2}{|c|}{ Ni(II) content } & \multirow{2}{*}{$\mathrm{N} / \mathrm{Ni}$} & \multirow{2}{*}{ Complex color } & \multirow{2}{*}{$\begin{array}{c}\text { DR UV-Vis-NIR } \\
\lambda_{\max }, \mathrm{nm}\end{array}$} \\
\hline & & wt.\% & $\mathrm{mmol} / \mathrm{g}$ & & & \\
\hline & $\mathrm{NiCl}_{2} \cdot 6 \mathrm{H}_{2} \mathrm{O}$ & & & & bright green & $1264,766,414$ \\
\hline & $\mathrm{Ni}(\mathrm{AcO})_{2} \cdot 4 \mathrm{H}_{2} \mathrm{O}$ & & & & yellow & 1120, 674, 392 \\
\hline 2.1 & $\mathrm{NiCl}_{2} \cdot 6 \mathrm{H}_{2} \mathrm{O}$ & 4.65 & 0.79 & 2.95 & green & 988,610 \\
\hline 2.2 & $\mathrm{NiCl}_{2} \cdot 6 \mathrm{H}_{2} \mathrm{O}$ & 4.79 & 0.82 & 3.98 & blue & 1008, 615, 383 \\
\hline 2.3 & $\mathrm{NiCl}_{2} \cdot 6 \mathrm{H}_{2} \mathrm{O}$ & 4.72 & 0.80 & 4.95 & sapphire & 1005, 583, 307 \\
\hline 2.1 & $\mathrm{Ni}(\mathrm{AcO})_{2} \cdot 4 \mathrm{H}_{2} \mathrm{O}$ & 4.88 & 0.83 & 3.10 & green & 1019, 615, 370 \\
\hline 2.2 & $\mathrm{Ni}(\mathrm{AcO})_{2} \cdot 4 \mathrm{H}_{2} \mathrm{O}$ & 4.65 & 0.79 & 4.13 & blue & 966, 598, 366 \\
\hline 2.3 & $\mathrm{Ni}(\mathrm{AcO})_{2} \cdot 4 \mathrm{H}_{2} \mathrm{O}$ & 4.80 & 0.82 & 4.83 & violet & $980,568,358$ \\
\hline
\end{tabular}

equal about 3 were green in color. Those with DETA moieties and N/Ni ratio equal about 4 were blue. The ratio equal around 5 noted for the complexes bearing TAEA resulted in sapphire or violet.

The synthesized complexes were characterized by DR UV-Vis-NIR and FTIR methods. The representative spectra are presented in Figure 1 and Figure 2, respectively. The coordination of $\mathrm{Ni}(\mathrm{II})$ ions by the polyamine ligands resulted in shifting the maxima of absorption observed in the DR UV-Vis-NIR spectra respectively for $\mathrm{NiCl}_{2} \cdot 6 \mathrm{H}_{2} \mathrm{O}$ ions at 413,763 and $1259 \mathrm{~nm}$ and for $\mathrm{Ni}(\mathrm{OAc})_{2} \cdot 4 \mathrm{H}_{2} \mathrm{O}$ at 391,673 and $1127 \mathrm{~nm}$ to the range of higher energy (Figure 1). The observed changes, particularly those in the visible range correlated with the final colors of the complexes.

The immobilization of Ni(II) ions by the resins with polyamine moieties resulted in changes in the FTIR spectra, as well. The differences in absorption in the range of $3400-2100 \mathrm{~cm}^{-1}$ were observed for the polymer supported $\mathrm{Ni}(\mathrm{II})$-amine complexes compared with the spectra of the polyamine resins (Figure 2). These changes proved involving amine groups in coordination of $\mathrm{Ni}(\mathrm{II})$ ions. Furthermore, the strong absorption bands in the range characteristic of acetate ions (at c.a. 1560 and $1390 \mathrm{~cm}^{-1}$ ) were noted in the spectra of the complexes derived from $\mathrm{Ni}(\mathrm{AcO})_{2} \cdot 4 \mathrm{H}_{2} \mathrm{O}$. These findings proved that acetate ions were immobilized together with $\mathrm{Ni}(\mathrm{II})$ ions (Figure 2).

\subsection{The Affinity of the Amine Resins to Palladium(II) Ions}

The affinity of resins 1.1-1.3 and 2.1-2.3 in relation to $\mathrm{Pd}(\mathrm{II})$ ions was studied similarly to the methodology 


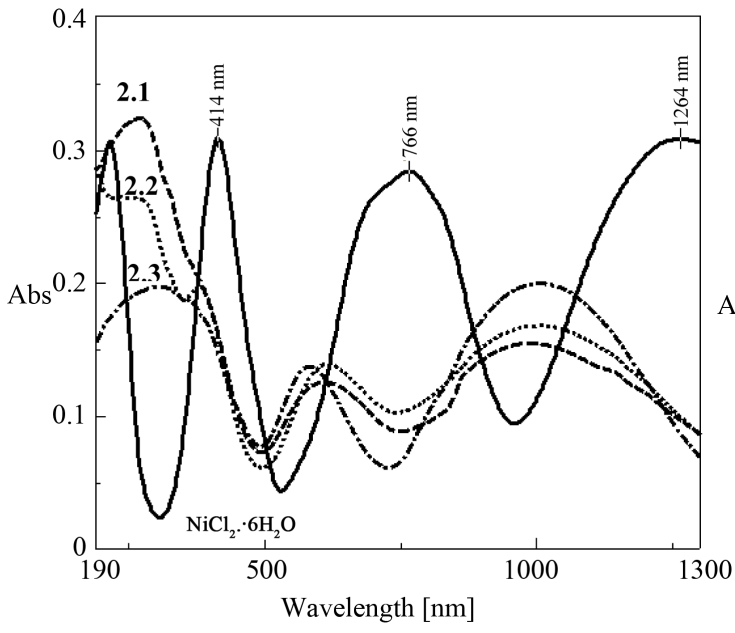

(a)

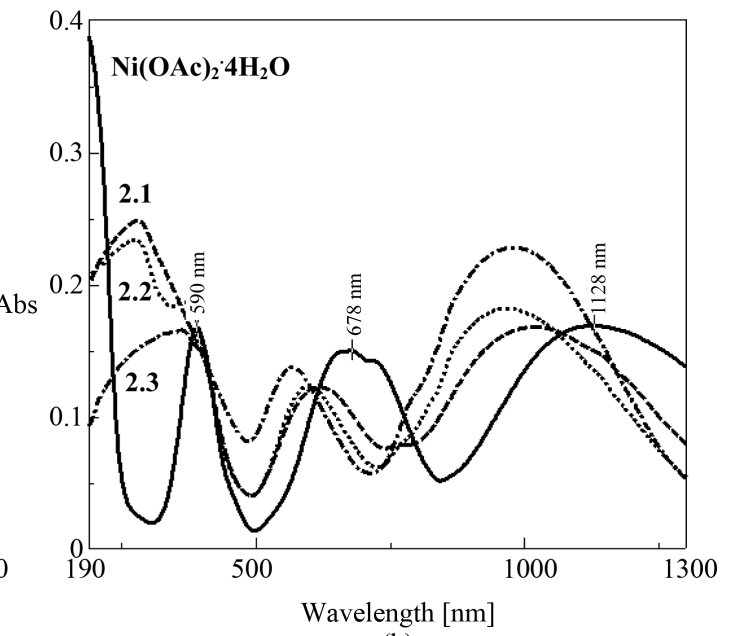

(b)

Figure 1. DR-UV-Vis-NIR spectra of polymer supported Ni(II)-polyamine 2.1-2.3 complexes derived from$\mathrm{NiCl}_{2} \cdot 6 \mathrm{H}_{2} \mathrm{O}(\mathrm{a})$ and $\mathrm{Ni}(\mathrm{AcO})_{2} \cdot 4 \mathrm{H}_{2} \mathrm{O}($ b), respectively.
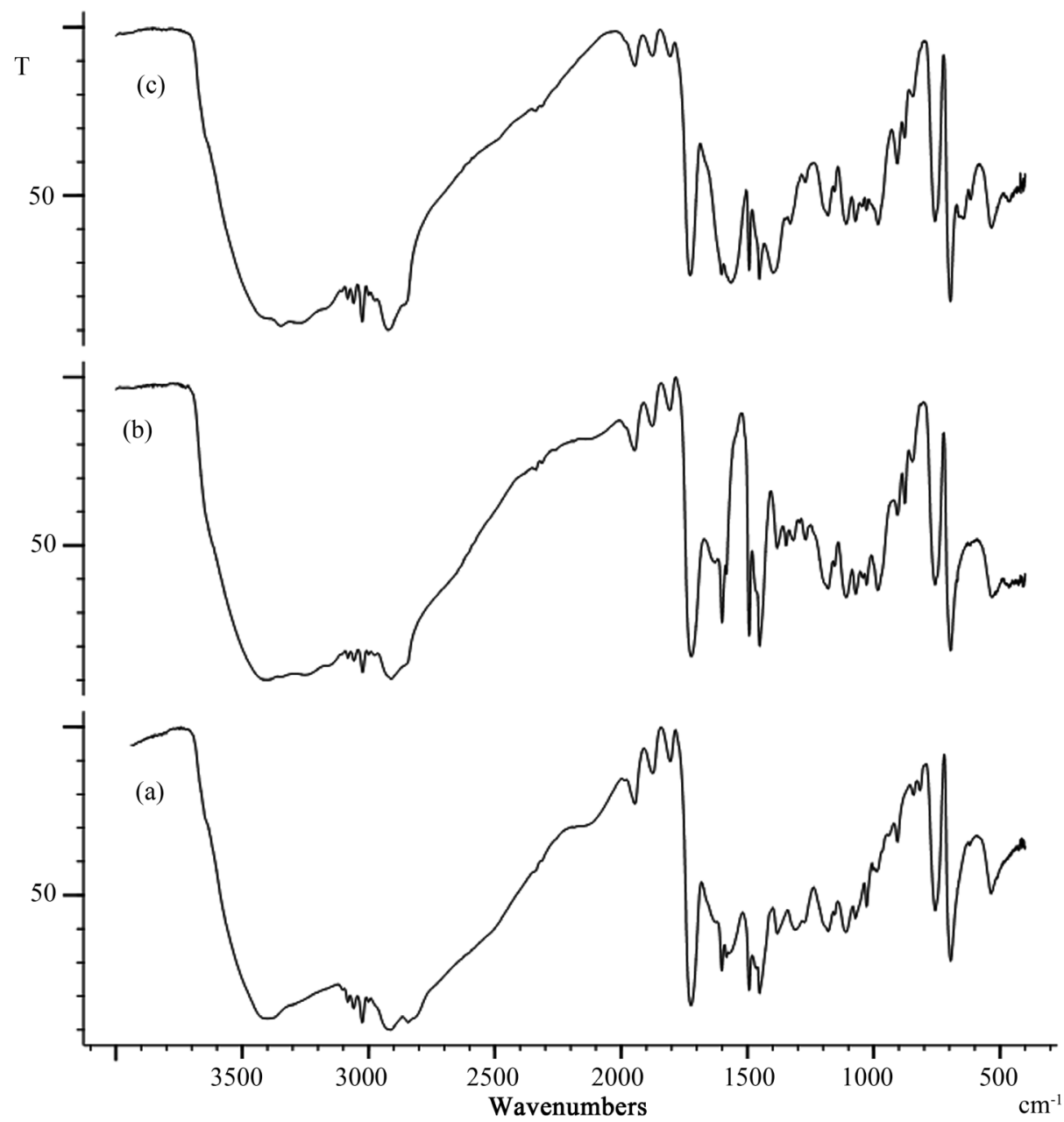

Figure 2. FT-IR spectra of polyamine resin 2.3 (a) and its polymer supported Ni(II)-polyamine complexes derived from $\mathrm{NiCl}_{2} \cdot 6 \mathrm{H}_{2} \mathrm{O}$ (b) and $\mathrm{Ni}(\mathrm{AcO})_{2} \cdot 4 \mathrm{H}_{2} \mathrm{O}$ (c), respectively. 
applied for $\mathrm{Ni}(\mathrm{II})$ ions. However, in this case methanol and its mixtures with methylene chloride turned out to be an improper medium for exploring the scavenging ability of the resins in respect to $\mathrm{Pd}(\mathrm{II})$ ions since $\mathrm{MeOH}$ caused the reduction of $\mathrm{Pd}(\mathrm{II})$ ions to $\mathrm{Pd}(0)$ particles. That is why the experiments with $\mathrm{Pd}(\mathrm{II})$ ions were performed in THF and its mixtures with water. The solutions of $\mathrm{Pd}\left(\mathrm{CH}_{3} \mathrm{COO}\right)_{2}$ in these solvents are stable within many hours. The results of the performed experiments are presented in Table 4.

It was found that resins $\mathbf{1 . 1}$ and $\mathbf{2 . 1}$ were able to remove up to $90 \% \mathrm{Pd}(\mathrm{II})$ ions dissolved in THF within 5 - 10 min. In consequence, the complete discoloration of the solutions was observed within next 5 min. However, resins 1.2-1.3 and 2.2-2.3, with DETA and TAEA moieties, respectively, were nearly inactive under the same conditions. The last were able to remove only $4 \%-11 \%$ of the dissolved Pd(II) ions within $60 \mathrm{~min}$. As a result, the initial brown color of the Pd(II) ion solutions remained nearly unchangeable in these cases.

The ability of resins 1.2-1.3 and 2.2-2.3 to uptake Pd(II) ions increased dramatically when water was added to THF. It was found that the presence of water, even in the relatively small quantity (5 vol-\%), so strongly activated the resins bearing DETA and TAEA moieties that they were able to immobilize the majority of Pd(II) ions from the model solutions within around 5 min (Figure 3, Table 4). The resins remained very active in relation to $\mathrm{Pd}(\mathrm{II})$ ions even if $1: 1 \mathrm{v} / \mathrm{v}$ THF-water mixture was used as a medium. They showed then the similar affinity to Pd(II) ions (Table 4). However, a decrease in resin reactivity in relation to Pd(II) ions could be observed, particularly for the resins with TAEA functionalities when an excess of water in relation to THF was used.

Based on the obtained results we concluded that the relatively good swelling ability of the polyamine resins in THF (Figure 4) was an insufficient factor for achieving the high reactivity of amine groups in relation to Pd(II) ions, particularly in the cases of the high loadings of these groups, i.e. for the resins with DETA and TAEA functionalities. Insufficient compatibility of THF with amine groups causes probably "closing” these polar groups inside the swelled hydrophobic polymer core making them inaccessible for Pd(II) ions. The synergic effect of the both solvents, THF and water, activates the resins thanks to interactions of the "closed" amine groups with the molecules of water transported by THF molecules to inside of the swelled polymer beads. However, an excess of water causes shrinkage of the resin beads due to incompatibility of their hydrophobic core with this

Table 4. Characteristics of the polymer supported polyamine-Ni(II) complexes.

\begin{tabular}{|c|c|c|c|}
\hline Polyamine resin & Solvent & Time (min) & Pd(II) ion uptake (\%) \\
\hline \multirow{4}{*}{1.1} & \multirow{2}{*}{ THF } & 5 & 95 \\
\hline & & 10 & 99 \\
\hline & \multirow{2}{*}{ THF- $\mathrm{H}_{2} \mathrm{O}(1: 1 \mathrm{v}: \mathrm{v})$} & 5 & 96 \\
\hline & & 10 & 99 \\
\hline \multirow{2}{*}{1.2} & THF & 60 & 5 \\
\hline & THF- $\mathrm{H}_{2} \mathrm{O}(1: 1 \mathrm{v}: \mathrm{v})$ & 5 & 98 \\
\hline \multirow{5}{*}{1.3} & THF & 60 & 8 \\
\hline & \multirow{2}{*}{ THF- $\mathrm{H}_{2} \mathrm{O}(20: 1 \mathrm{v}: \mathrm{v})$} & 5 & 92 \\
\hline & & 10 & 99 \\
\hline & THF- $\mathrm{H}_{2} \mathrm{O}(1: 1 \mathrm{v}: \mathrm{v})$ & 10 & 99 \\
\hline & THF- $\mathrm{H}_{2} \mathrm{O}(1: 2 \mathrm{v}: \mathrm{v})$ & 60 & 4 \\
\hline \multirow{3}{*}{2.1} & THF & 10 & 99 \\
\hline & \multirow{2}{*}{ THF- $\mathrm{H}_{2} \mathrm{O}(1: 1 \mathrm{v}: \mathrm{v})$} & 5 & 87 \\
\hline & & 60 & 98 \\
\hline \multirow{3}{*}{2.2} & THF & 60 & 4 \\
\hline & \multirow{2}{*}{ THF- $\mathrm{H}_{2} \mathrm{O}(1: 1 \mathrm{v}: \mathrm{v})$} & 5 & 86 \\
\hline & & 60 & 90 \\
\hline \multirow{3}{*}{2.3} & THF & 60 & 11 \\
\hline & \multirow{2}{*}{ THF- $\mathrm{H}_{2} \mathrm{O}(1: 1 \mathrm{v}: \mathrm{v})$} & 5 & 84 \\
\hline & & 60 & 98 \\
\hline
\end{tabular}




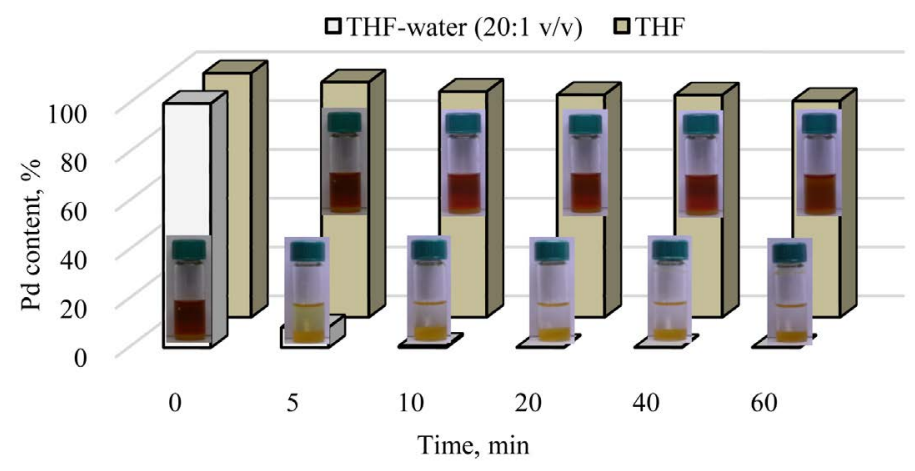

Figure 3. Comparison of the uptake of Pd(II) ions by the polyamine resins 1.3 in THF and 1:1 v/v THF-water system.

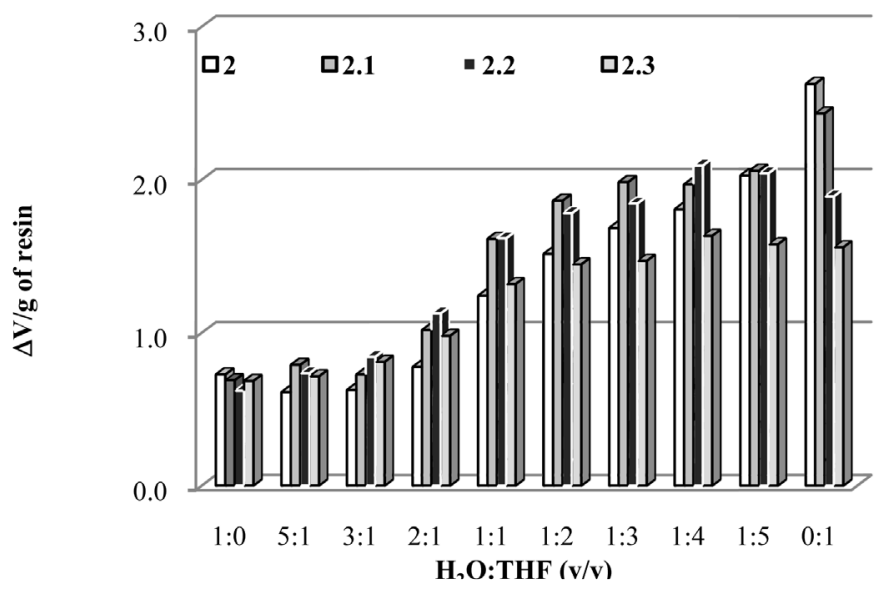

Figure 4. Swelling ability of the GMA resin 2 and the polyamine functionalized resins 2.1-2.3.

solvent and, in consequence, "re-closing” $\mathrm{NH}_{2}$ groups inside of the beads occurs.

The samples of the selected amine resins were also treated with the solutions of $\operatorname{Pd}(\mathrm{II})$ ions in $1: 1 \mathrm{v} / \mathrm{v}$ THF-water mixture for 24 hours to prepare the catalysts for Suzuki-Miaura coupling reactions. The characteristics of these catalysts were presented in our previous work [20]. The polymer supported Pd(II)-polyamine complexes consisted of up to 16.4 wt.\% palladium could be obtained in this way. The complexes derived from $\mathbf{2 . 1}$ and 2.2 were characterized by the similar N/Pd ratio, equals about 2.5. The N/Pd ratio calculated for the complex derived from 2.3, bearing TAEA moieties, amounted to about 3.

\subsection{Competitive Sorption of the Metal Ions}

To compare the reactivity of the resins in relation to $\mathrm{Cu}(\mathrm{II}), \mathrm{Ni}(\mathrm{II})$ and $\mathrm{Pd}(\mathrm{II})$ ions a series of the further experiments were performed in which resins 2.1-3 were treated with the solutions consisting of the mixture of $\mathrm{Cu}(\mathrm{II})$, $\mathrm{Ni}(\mathrm{II})$ and $\mathrm{Pd}(\mathrm{II})$ acetates (in the equimolar quantities) in 1:1 v:v THF-water mixture. The molar ratios of Pd(II) to $\mathrm{Cu}(\mathrm{II})$ ions and $\mathrm{Pd}(\mathrm{II})$ to $\mathrm{Ni}(\mathrm{II})$ ions loaded on the resins calculated based on the results of the elementary analysis are presented in Table 5. The experiments revealed the clearly higher affinity of the resins to $\mathrm{Pd}(\mathrm{II})$ ions compared to $\mathrm{Cu}(\mathrm{II})$ and $\mathrm{Ni}(\mathrm{II})$ ions. Furthermore, it was noted that the $\mathrm{Pd} / \mathrm{Cu}$ ratio depended on the nature of the polyamine moiety. It was the least for $\mathbf{2 . 1}$ bearing EDA functionalities and the highest for 2.2 with DETA functionalities. The Pd/Ni ratio turned out to be comparable for the all explored resins. The very low values of the loadings of $\mathrm{Ni}(\mathrm{II})$ ions revealed the low affinity of the explored resins to these ions in the THF-water medium.

\subsection{The Affinity of the Amine Resins to Acyl and Sulphonyl Chlorides}

Resins 2.1-2.3 showed the diversity in chemical affinity to acid chlorides in a medium of methylene chloride, as 
well. It was observed nearly immediate quantitative removing acyl chlorides from the solutions by resin 2.1 with EDA functionalities. However, the efficiency of this resin in scavenging sulfonyl chloride was clearly less. Resin 2.1 was able to remove about $90 \%$ sulfonyl chloride from the solution within 60 min (Table 6). Resin 2.2

Table 5. Results of the competitive uptake of $\mathrm{Pd}(\mathrm{II}), \mathrm{Cu}(\mathrm{II})$ and $\mathrm{Ni}(\mathrm{II})$ ions by the selected polyamine resins; solvent-1:1 v/v THF-water, time $24 \mathrm{hr}$.

\begin{tabular}{cccccccc}
\hline \multirow{2}{*}{ Polyamine resin } & \multicolumn{2}{c}{ Pd(II) content } & \multicolumn{2}{c}{$\mathrm{Cu}(\mathrm{II})$ content } & \multicolumn{2}{c}{$\mathrm{Ni}(\mathrm{II})$ content } \\
\cline { 2 - 7 } & $\%$ & $\mathrm{mmol} / \mathrm{g}$ & $\%$ & $\mathrm{mmol} / \mathrm{g}$ & $\%$ & $\mathrm{mmol} / \mathrm{g}$ \\
\hline $\mathbf{2 . 1}$ & 6.71 & 0.64 & 0.20 & 0.03 & 0.02 & 0.01 \\
2.2 & 10.80 & 1.01 & 2.61 & 0.41 & 0.03 & 0.01 \\
2.3 & 9.38 & 0.88 & 0.52 & 0.08 & 0.03 & 0.01 \\
\hline
\end{tabular}

Table 6. Uptake of acyl and sulphonyl chlorides by the polyamine resins.

\begin{tabular}{|c|c|c|c|}
\hline Acyl, Sulphonyl chlorides & Polyamine resin & Time (min) & Acid chloride uptake (\%) \\
\hline & 2.1 & 5 & 100 \\
\hline & 2.2 & 10 & 100 \\
\hline 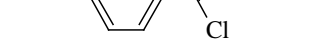 & 2.3 & 10 & 40 \\
\hline & 2.3 & 120 & 97 \\
\hline & 2.1 & 5 & 100 \\
\hline & 2.2 & 5 & 99 \\
\hline & 2.3 & 20 & 100 \\
\hline & 2.1 & 5 & 100 \\
\hline & 2.2 & 5 & 98 \\
\hline & 2.3 & 10 & 93 \\
\hline & 2.1 & 5 & 100 \\
\hline & 2.2 & 5 & 86 \\
\hline & 2.3 & 10 & 96 \\
\hline & 2.1 & 5 & 100 \\
\hline & 2.2 & 5 & 40 \\
\hline & 2.2 & 20 & 100 \\
\hline & 2.3 & 5 & 79 \\
\hline & 2.3 & 10 & 100 \\
\hline & 2.1 & 5 & 100 \\
\hline & 2.2 & 5 & 71 \\
\hline & 2.2 & 10 & 95 \\
\hline & 2.3 & 10 & 32 \\
\hline & 2.3 & 90 & 99 \\
\hline & 2.1 & 5 & 53 \\
\hline & 2.1 & 180 & 97 \\
\hline & 2.2 & 5 & 44 \\
\hline $\mathrm{Cl}$ & 2.2 & 120 & 97 \\
\hline & 2.3 & 5 & 66 \\
\hline & 2.3 & 40 & 100 \\
\hline & 2.1 & 5 & 54 \\
\hline & 2.1 & 180 & 97 \\
\hline & 2.2 & 5 & 74 \\
\hline & 2.2 & 120 & 94 \\
\hline & 2.3 & 5 & 63 \\
\hline & 2.3 & 40 & 100 \\
\hline
\end{tabular}


with DETA moieties turned out to be less reactive. The quantitative removing of acyl chlorides took this resin about 20 min in most cases. Only 2-chlorobenzoyl chloride was removed by resin 2.2 within 60 min. The efficiency of resin 2.2 in removing sulphonyl chlorides was higher than that observed for resin 2.1. These chlorides were scavenged by resin 2.2 with $94 \%$ - 97\% yield within 120 min. Resin 2.3 with TAEA functionalities removed 2-chloro- and 4-chlorobenzoyl chlorides faster than other chlorides. Benzoyl and phenylacetyl chlorides were removed by this resin quantitatively within 120 min. Resin 2.3 enabled quantitative removing sulphonyl chlorides within about 60 min.

The chemical nature of immobilization of acid chlorides on the amine functionalized resins was proved by FTIR method. The absorption bands at 1650 and $1530 \mathrm{~cm}^{-1}$ indicated that the polymer supported amides were formed during catching acyl chlorides by the amine resins. The formation of sulfonamides resulted in decreasing absorption at $1550 \mathrm{~cm}^{-1}$, in the range characteristic of $\mathrm{N}-\mathrm{H}$ deformational stretches, and increasing absorption at 1350 and $1150 \mathrm{~cm}^{-1}$, in the range characteristic of $\mathrm{O}=\mathrm{S}=\mathrm{O}$ stretches [21].

\section{Conclusions}

The EDA, TETA and TAEA functionalized gels derived from the low cross-linked terpolymers of glycidyl metacrylate and styrene (the GMA resins) are capable to remove $\mathrm{Cu}(\mathrm{II}), \mathrm{Ni}(\mathrm{II})$ and $\mathrm{Pd}(\mathrm{II})$ ions and acid chlorides from organic solutions. However, their affinity to particular metal ions depends not only on the nature of the polyamines immobilized on the gel type resins but also on the mutual compatibility of solvent molecules, hydrophobic polymer cores, and polyamine moieties. It is found that a single solvent is sometimes insufficient to activate the donor properties of the amine functionalized resins. To remove the aforementioned metal ions from solutions quantitatively, the mixed solvent systems should be then used. The solvents have to be capable to swell the resins and interact with the donor groups, simultaneously.

The resin with EDA moieties is able to remove acyl chlorides from methylene chloride solution. However, it is not fully effective in scavenging sulphonyl chlorides. The last electrophiles are caught effectively within relatively short time by the resin with TAEA moieties.

\section{References}

[1] Beller, M. and Bolm, C. (2004) Transition Metals for Organic Synthesis: Building Blocks and Fine Chemicals. WILEY-VCH Verlag GmbH \& Co. KGaA, Weinheim.

[2] Tulla-Puche, J. and Albericio, F., Eds. (2008) The Power of Functional Resins in Organic Synthesis. WILEY-VCH Verlag GmbH \& Co. KGaA, Weinheim. http://dx.doi.org/10.1002/9783527626175

[3] Urawa, Y., Miyazawa, M., Ozeki, N. and Ogura, K. (2003) A Novel Methodology for Efficient Removal of Residual Palladium from a Product of the Suzuki-Miyaura Coupling with Polymer-Supported Ethylenediamine Derivatives. Organic Process Research \& Development, 7, 191-195. http://dx.doi.org/10.1021/op0255682

[4] Nastasović, A., Jovanović, S., Đorđević, D., Onjia, A., Jakovljević, D. and Novaković, T. (2004) Metal Sorption on Macroporous Poly(GMA-co-EGDMA) Modified with Ethylene Diamine. Reactive \& Functional Polymers, 58, 139147. http://dx.doi.org/10.1016/j.reactfunctpolym.2003.11.015

[5] Welch, Ch.J., Albaneze-Walker, J., Leonard, W.R., Biba, M., DaSilva, J., Henderson, D., Laing, B., Mathre, D.J., Spencer, S., Bu, X. and Wang, T.B. (2005) Adsorbent Screening for Metal Impurity Removal in Pharmaceutical Process Research. Organic Process Research \& Development, 9, 198-205. http://dx.doi.org/10.1021/op049764f

[6] Barbaras, D., Brozio, J., Johannsen, I. and Allmendinger, T. (2009) Removal of Heavy Metals from Organic Reaction Mixtures: Preparation and Application of Functionalized Resins. Organic Process Research \& Development, 13, 10681079. http://dx.doi.org/10.1021/op900102a

[7] Liu, Ch.K., Bai, R. and Ly, Q.S. (2008) Selective Removal of Copper and Lead Ions by Diethylenetriamine-Functionalized Adsorbent: Behaviors and Mechanisms. Water Research, 42, 1511-1522. http://dx.doi.org/10.1016/j.watres.2007.10.031

[8] Yu, Z.Y., Wu, R.A., Wu, M.H., Zhao, L., Li, R.B. and Zou, H.F. (2010) Preparation of Polyamine-Functionalized Copper Specific Adsorbents for Selective Adsorption of Copper. Colloids and Surfaces B: Biointerfaces, 78, 222-228. http://dx.doi.org/10.1016/j.colsurfb.2010.03.004

[9] Chouyyok, W., Shin, Y., Davidson, J., Samuels, W.D., Lafemina, N.H., Rudledge, R.D. and Fryxell, G.E. (2010) Selective Removal of Copper(II) from Natural Waters by Nanoporous Sorbents Functionalized with Chelating Diamines. Environmental Science \& Technology, 44, 6390-6395. http://dx.doi.org/10.1021/es101165c

[10] Jermakowicz-Bartkowiak, D. (2010) Polymer Resins for Recovery of Valuable Metals. Environmental Geochemistry 
and Health, 32, 317-320. http://dx.doi.org/10.1007/s10653-010-9303-0

[11] Kaldor, S.W., Siegel, M.G., Fritz, J.E., Dressman, B.A. and Hahn, P.J. (1996) Use of Solid Supported Nucleophiles and Electrophiles for the Purification of Non-Peptide Small Molecule Libraries. Tetrahedron Letters, 37, 7193-7196. http://dx.doi.org/10.1016/0040-4039(96)01636-X

[12] Kaldor, S.W., Fritz, J.E., Tang, J. and McKinney, E.R. (1996) Discovery of Antirhinoviral Leads by Screening a Combinatorial Library of Ureas Prepared Using Covalent Scavengers. Bioorganic\& Medicinal Chemistry Letters, 6, 30413043. http://dx.doi.org/10.1016/S0960-894X(96)00560-4

[13] Flynn, D.L., Crich, J.Z., Devraj, R.V., Hockerman, S.L., Parlow, J.J., South, M.S. and Woodard, S. (1997) Chemical Library Purification Strategies Based on Principles of Complementary Molecular Reactivity and Molecular Recognition. Journal of the American Chemical Society, 11, 4874-4881. http://dx.doi.org/10.1021/ja963462e

[14] Booth, R.J. and Hodges, J.C. (1997) Polymer-Supported Quenching Reagents for Parallel Purification. Journal of the American Chemical Society, 119, 4882-4886. http://dx.doi.org/10.1021/ja9634637

[15] Bukowska, A., Bukowski, W. and Noworól, J. (2007) Three-Component Terpolymers of Glycidyl Methacrylate with Good Swelling Characteristics. Journal of Applied Polymer Science, 106, 3800-3807. http://dx.doi.org/10.1002/app.26009

[16] Bukowska, A. and Bukowski, W. (2012) Polyamine Functionalized Glycidyl Methacrylate Terpolymers as Scavengers for Metal Ions Uptake from Organic Solutions. Journal of Applied Polymer Science, 124, 904-914. http://dx.doi.org/10.1002/app.35123

[17] Ferreira, S.L.C., Costa, A.C.S. and de Jesus, D.S. (1996) Derivative Spectrophotometric Determination of Nickel Using Br-PADAP. Talanta, 43, 1649-1656. http://dx.doi.org/10.1016/0039-9140(96)01919-4

[18] Hubicki, Z. and Leszczyńska, M. (2005) Sorption of Palladium(II) Chloride Complexes on Weakly, Intermediate and Strongly Basic Anion Exchangers. Desalination, 175, 227-236. http://dx.doi.org/10.1016/j.desal.2004.10.010

[19] Watkins, C.L. and Vigee, G.S. (1976) An Investigation of Ethylenediamine Complexes of Copper(II) and Nickel(II) in Solutions of Dimethyl Sulfoxide. Journal of Physical Chemistry, 80, 83-88. http://dx.doi.org/10.1021/j100542a018

[20] Bester, K., Bukowska, A. and Bukowski, W. (2013) Palladium Catalysts Supported on Amine-Functionalized Glycidyl Methacrylate Gel Type Terpolymers. Synthesis, Characteristics and Study of Catalytic Activity in Suzuki-Miyaura Reactions. Journal of Molecular Catalysis A-Chemical, 378, 124-134. http://dx.doi.org/10.1016/j.molcata.2013.06.003

[21] Pretsch, E., Bühlmann, P. and Badertscher, M. (2009) Structure Determination of Organic Compounds. Springer-Verlag, Berlin and Heidelberg. 